\title{
INVOLUÇÃO E OS CURRÍCULOS COTIDIANOS: A EFEMERIDADE DE UMA VIDA - CORPO
}

\section{INVOLUTION AND EVERYDAY CURRICULA: THE EPHEMERITY OF A BODY - LIFE}

\author{
Letícia Regina Silva Souza ${ }^{1}$ \\ Tamili Mardegan da Silva ${ }^{2}$
}

\begin{abstract}
Resumo: Trata-se de uma pesquisa interessada nos acontecimentos produzidos por uma docência-nômade nos territórios movediços da educação e que tem como um de seus principais objetivos pensar os processos de composição-encontro dos corpos que, em meio aos movimentos curriculares, têm a involução como potencializadora da própria vida. Para tanto, defende que as práticas-políticas se realizam por meio das experiências vivenciadas cotidianamente por educadores nos mais diversos-complexos territórios do ensino público, na efemeridade de uma vida-corpo, que rompem com o instituído. Interroga, portanto, os currículos tecidos rizomaticamente, na tensão entre molar e molecular, nos quais são experimentados os diferentes modos de existência, articulados aos processos de subjetivação. Apostando na pesquisa com os cotidianos, cartografa o caráter reacionário dos fazeres docentes que compõem na defesa de que, ao (in)voluírem, os professores traçam linhas de fuga e permitem que a educação seja aerada com possibilidades outras de se pensar os currículos.
\end{abstract}

Palavras-chave: Cotidianos; involução; currículos.

Abstract: This research focuses on events produced amongst nomadic teaching that takes place in non-static territories of education. It aims at thinking processes of composition and encounters of bodies whose lives are potentialized by involution amongst curricular movements. It argues that the ephemerality of teacher's everyday experiences in public schools give birth to a wide range of political practices, which, for their turn, mine practices that have been traditionally institutionalized. It assumes that different modes of existence emerge form molar-molecular tensions of rhyzomatic curricula through processes of subjectivity. Also, it infers that daily political practices require a non-hierarchical methodology. Thus, cartography is carried out in order to trigger thinking about everyday life practices to suggest that lines of scape are traced as teachers go through involution processes and provide education with unpredicted possibilities to problematize curricular relations.

Keywords: Everyday life; involution; school curricula.

\section{Introdução a uma escrita-ensaio}

Infinidades. Corpos. Cenas. Linhas. Traços. Palavras. Pontos. Rascunhos. Gestos. Sombras. Cores... Que juntos compõem os fluxos cartográficos experimentados na efemeridade de uma vidacorpo. ${ }^{3}$ Palavras, pontos, vazios que, fugazmente, num dado momento, são pensados como a última cena e o último corpo de, e... Uma vida na imanência dos seus devires, naquele instante, que estavam apenas num interstício de tempo, de vida e de desejo. Última fórmula.

\footnotetext{
${ }^{1}$ Universidade Federal do Espírito Santo - UFES. E-mail: le.reginna@gmail.com.

${ }^{2}$ Universidade Federal do Espírito Santo - UFES. E-mail: tamilimardegan@ hotmail.com.

${ }^{3} \mathrm{O}$ uso do hífen ligando duas ou mais palavras é uma aposta estética de composição e de intensificação do que queremos expressar. Desta forma, alternaremos as posições desses termos e de outros ao longo da escrita para despistarmos as possibilidades de hierarquias ou de sequencialidade, mas preservamos os sentidos próprios de cada palavra.
} 
Escrever não é tarefa fácil, assim como não é simples pesquisar. São atitudes que se assemelham na maneira pela qual ambas demandam uma procura constante, mas que nem sempre está associada ao encontro. As buscas pelas palavras e pelos problemas jogam os corpos em rumos incertos, tirando-os da terra firme e lançando-os em um mar estranhado. Diante do momento de partida, se torna intrínseca nos corpos dos escritores-pesquisadores a necessidade de se lançarem em uma escrita e em uma pesquisa que permitam o desprendimento do cais. A segurança, que outrora pensávamos ter, de pouco serve quando você se encontra em alto mar. As certezas ficaram lá trás. Pesquisar é preciso.

Para aprender a respeito desse novo modo de vida, em que o termo pesquisador se torna não só um substantivo, mas principalmente um adjetivo, é preciso mudar os rumos. Desaprender, desprender, estar sensível aos signos, usar o instinto e inventar problemas (DELEUZE, 2006), por meio deste aprender com a escrita-pesquisa-ensaio. E tecendo uma literatura menor (DELEUZE; GUATTARI, 2017) dentro da maior, na marginalidade e na resistência. Gaguejante. Vivendo na insubmissão de uma pesquisa que se torna uma práticapolítica, na qual não há problema em não se ter respostas prontas para todos os problemas, pois o objetivo não é responder às questões, mas, antes, sair delas (DELEUZE, PARNET, 1998).

A conexão do sentimento de incompletude do ensaio-escrita que aqui propomos, demonstra as aberturas dos movimentos imanentes possíveis pelo devir-pesquisadora $e$ devirprofessora $e$ devir-corpo $e$ devires... num processo que provoca um reterritorializar, de novo e sempre. Ritornelo. Um movimentar-se sem que seja preciso sair do lugar, provocando um retorno sempre diferente de quanto se partiu. Territórios múltiplos, espaços-tempos (ina)habitáveis, que traçam as linhas cartográficas, juntos às cenas produzidas pelos corpos em seus diferentes processos de involução.

Dessa maneira, estamos na defesa do conceito de um devir que é involutivo, pois preferimos chamar de involução essa forma de evolução que se faz entre heterogêneos e, sobretudo, carregada pela condição de que não se confunda a involução com uma regressão.

No devir não há passado, nem futuro, e sequer presente; não há história. Tratase, antes, no devir de involuir: não é nem regredir, nem progredir. Devir é tornar-se cada vez mais sóbrio, cada vez mais simples, tornar-se cada vez mais deserto e, assim, mais povoado. É isso que é difícil de explicar: a que ponto involuir, é evidentemente, o contrário de evoluir, mas também, o contrário de regredir, retornar à infância ou a mundo primitivo. Involuir é ter um andar cada vez mais simples, econômico, sóbrio [...]. Involuir é estar 'entre', no meio, adjacente. [...] (DELEUZE; PARNET, 1998, p. 24-25).

Logo, sentiremos, neste contexto, que a involução é criadora. Que, em outras palavras, "[...] involuir é formar um bloco que corre seguindo sua própria linha, entre os termos postos em jogo e sob as relações assinaláveis" (DELEUZE; GUATTARI, 2012a, p. 20). Partimos deste pressuposto conceitual de se pensar os acontecimentos que reverberam o involuir dos deviresdocentes, ou seja, o devir-ilimitado torna-se o próprio acontecimento, "[...] com todas as reviravoltas que lhe são próprias, do futuro e do passado, do ativo e do passivo, da causa e do efeito" (DELEUZE, 1974, p. 21).

Para Deleuze (1974), o acontecimento "deve ser querido", pois os acontecimentos se efetuam em nós, nos esperam, nos aspiram e nos "fazem sinal". E será em meio às práticaspolíticas docentes cotidianas que, sendo produzidas entre uma docência-pensamento nômade, tensionarão o espaço estriado na tentativa de criar novos espaços lisos. No acontecimentalizar dos seus efeitos e suas experiências produzirão currículos cotidianos em involução, na efemeridade de uma vida-corpo. 
Em meio às práticas-políticas cotidianas, que são produzidas entre uma docência $e$ um pensamento nômade, vemos serem inventados novos/outros possíveis que fazem da pesquisa uma escrita inquietada na dimensão propriamente micropolítica do texto que é a sua natureza cartográfica (ROLNIK, 2007). Assim, apostamos no que é tecido pelos sujeitos de forma tão potente e, de certa forma, tão anônima, nos territórios complexos desse mapa infinitivo que é o campo educacional, o que nos provoca a estranhar qualquer ideia que parta da simplificação dos processos: não há como descomplexificar o cotidiano ou reduzi-lo a um lugar fixo. Falamos de cotidiano(s), ora no singular, ora no plural. Multiplicidade.

Pensar com Deleuze e Guattari (1992) o singular distintamente do particular, se mostra como algo único, não generalizável e que não se sujeita a nenhum processo de unificação pela semelhança ou pela equivalência, não podendo por isso mesmo ser representado. E, embora não se possa generalizar o singular, pode-se repeti-lo e essa repetição é sempre uma recriação, ou seja, o aparecimento de um novo singular. Logo, toda criação é singular (DELEUZE; GUATTARI, 1992), uma a possibilidade de se conceber um movimento que vai de singular a singular, sem passar pelo geral. O universal, nesse caso, não é o geral, ao contrário, se diz da repetição diferencial do singular.

Desejamos forçar o pensamento... Pensar é o deslocar-se, é a ruptura, é o atravessamento com as verdades advindas do fora. Propomos o fora como um devir de forças que subtraem a história, dando ao pensamento sua tendência inatual e geográfica. Por que, então, se referir a tal pensamento como intempestivo? Devido à experimentação que entrelaça o ato de pensar, se fazendo antagônica aos pensamentos instituídos pelas verdades absolutas e determinadas pelo consenso sócio-político a qual somos parte e nele (re)existimos cotidianamente.

Nos hiatos e nas rupturas existem combinações que desmembram ou abraçam e percebemos que isso faz parte do rizoma-educação. São linhas de intensidade que se arrebentam em todas as direções, escapam da perseguição totalizadora e fazem contato com outras raízes, seguindo outras direções para se tornar o pesadelo do pensamento nivelado. Esse intermezzo é a nossa aposta para experienciarmos os fluxos rizomáticos que estão por dentro das estruturas.

\section{Inquietude de pesquisar com}

Pesquisar com os cotidianos (FERRAÇO, 2003) nos têm feito pensar constantemente a respeito da vida e das vidas que os compõem. Vidas de uma vida... Cotidianos que se manifestam no vivido, porque falam da própria vida. Ao mesmo passo, nos permitem ensinamentos, especialmente, a respeito da educação pública, nos provocando a pensar o quanto ainda é preciso aprender e se inquietar sempre e a todo momento, entre idas e vindas. Como é provocativo se imaginar um pesquisador que, ao mergulhar nesse vivido, se torna uma vida que também faz parte do que está sendo pesquisado ou do que se pretende pesquisar.

A pesquisa com os cotidianos é uma perspectiva metodológica que concebe a educação por meio dos cortes e recortes que podem provocar tensão nas estruturas e nas formas molares de se conceber os currículos em seus fluxos, possibilitando-nos “[...] desterritorializar o inimigo através da ruptura interna de seu território, desterritorializar-se a si mesmo renunciando, indo a outra parte... Uma outra justiça, um outro movimento, um outro espaço-tempo" (DELEUZE; GUATTARI, 2012b, p. 14).

A cotidianidade da educação é múltipla, carregada de sentidos e nuances. Lidamos com o incontrolável, com o caótico, com o imprevisível, mas também com o molar, com o fixo e com o instituído. É uma coisa e outra. Desejamos encontrar uma melodia que componha e perpasse transversalmente por entre os interstícios de traduções e experiências dos corpos. Tudo se desfaz num espaço movediço, incerto e inconsistente. Problematizamos, portanto, por meio 
das pesquisas com os cotidianos e os referenciais antifundamentalistas, as cenas-corpos que potencializam um currículo $e$ os currículos.

A pesquisa com os cotidianos está atravessada por diferentes movimentos que agem "[...] abrindo brechas que desafiam o instituído" (FERRAÇO, 2005, p. 9), o que, a nosso ver, proporciona a dimensão de complexidade para a educação em que investimos, ou seja, complexo por ser tecido junto ao cotidiano vivido (FERRAÇO, 2005). Em meio às práticas-políticas de currículo e compondo com o que está proposto tradicionalmente nos documentos prescritivos, estão as microações que nos ajudam a sustentar a ideia de complexidade da educação (FERRAÇO, 2006).

Nas problematizações enredadas de uma pesquisa que trata das vidas-corpos, a vivacidade das múltiplas práticas educativas cotidianas e as redes de currículos negligenciadas pelos sistemas educacionais são discutidas por Ferraço (2011, p12), que ao trazer a potência do currículo realizado nos propõe que:

[...] a intenção de ajudar a pensar na potência dos diferentes e múltiplos currículos que estão sendo realizados cotidianamente pelos educadores e pelos alunos, em diferentes contextos escolares, mas não são tidos como legítimos e/ou dignos de importância, uma vez que burlam, escapam, transgridem as metodologias e conteúdos propostos pelos discursos governamentais.

Na perspectiva da micropolítica, buscamos situar as discussões no plano das afecções e das relações intensas vivenciadas nos contextos da educação e da pesquisa. Quando não há a captura dos microprocessos de desejo, quando se escapa e revoluciona cotidianamente, as máquinas produtivas capitalísticas funcionam mal, entram em colapso e conseguimos, nas ações molecularizadas, a possibilidade de não usar um só modo de referência (GUATTARI; ROLNIK, 2017), ou seja, “A questão da micropolítica é a de reproduzirmos (ou não) os modos de subjetivação dominante" (Ibidem, p. 155).

De maneira semelhante, com Deleuze e Guattari (2011, p. 61-62), pensamos não ser possível separar árvore (macropolítica de concepções molares) e rizoma (micropolítica de concepções moleculares), porque ambos estão relacionados pelos movimentos transversais. Não há polarização quando tratamos dessas multiplicidades:

Não se trata, no entanto, de opor [...] as máquinas molares e moleculares, segundo um dualismo que não seria melhor que o do Uno e do múltiplo. Existem unicamente multiplicidades de multiplicidades que formam um mesmo agenciamento, que se exercem no mesmo agenciamento: as matilhas nas massas e inversamente. As árvores têm linhas rizomáticas, mas o rizoma tem pontos de arborescência.

Assim, consideramos que "As multiplicidades são rizomáticas e denunciam as pseudomultiplicidades arborescentes" (DELEUZE; GUATTARI, 2011, p. 23), o que mostra o desejo de, a partir do múltiplo, produzir sentidos para os detalhes cotidianos enredados nas totalidades do que é instituído. Falamos, então, de multiplicidades que se encontram e explodem em produções curriculares, expressando a inexistência de um pivô para o currículo.

Combatendo a totalidade falida dos currículos oficiais e a sua desejada unicidade hegemônica, evidenciamos os currículos tecidos cotidianamente, os quais produzem aprendizagens e performances, entre o caos e a ordem. Os corpos-cenas ocupam e falam de diferentes lugares, divulgam e/ou ocultam o que nos faz bem. Duvidamos. Isso diz respeito aos efeitos dos agenciamentos em que nós, pesquisadores-professores, não somos mais nós mesmos, mas estamos sempre sendo ajudados, aspirados, multiplicados (DELEUZE; GUATTARI, 2011). 
Somos muitos, somos únicos, individuais-coletivos. Um plano de composição espinosano em que um corpo afeta outros corpos, ou é afetado por outros corpos: nesse afetar e ser afetado, o que também define um corpo na sua individualidade (DELEUZE, 2002). E, com o passar do tempo, percebemos que são inúmeros os questionamentos que surgem no sistema maquínico desse viver-ser involutivo de uma professora. Esses cotidianos nos tocam e fazem pulsar o desejo de um experimentar aguçado, bem como de uma escuta potente e um olhar sensível que se constitui nos cotidianos em seus diferentes espaços-tempos. E, ainda, nesse pesquisar, perceber que só olhar não basta, é preciso farejar, preparar o corpo, sentir o pelo arrepiar, como um animal à espreita em busca da sua caça (DELEUZE, 2005).

Esse cotidiano nos apresenta um currículo provisório, emaranhado de histórias vividas e significativas, constituídas pelas relações de força e de composição dos corpos. Assim, diante das infinitas forças do cotidiano, nos deparamos com aqueles devires da pesquisa que nos sacodem e nos trazem de volta, nos remetendo ao novo. Diferença e repetição. Como diriam Deleuze e Parnet (1998, p. 10), "Devir é jamais imitar, nem fazer como, nem ajustar-se a um modelo, seja ele de justiça ou verdade".

Por concebermos o currículo para além de uma mera lista de objetos e habilidades, percebemos o processo educacional como um rizoma, sem início ou fim, um movimento que germina pelo meio, "[...] o meio e não o começo nem o fim, a grama que está no meio e que brota pelo meio, e não as árvores que têm um cume e raízes. Sempre a grama entre as pedras do calçamento" (DELEUZE; PARNET, 1998, p. 20).

Dessa forma, nos movemos em direção a uma metodologia inacabada, aberta, que vai se entrecruzando durante todo o processo, sem desejar previsões. Cartografar. Pesquisar com e não sobre. Essa é a proposta metodológica que assumimos. Assim como o escopo desta pesquisa, uma metodologia efêmera, buscando uma geografia que vai se constituindo em meio, no meio, com o meio. Um risco assumido para defendermos um modo um tanto quanto anti-hegemônico de pesquisar aquilo que não cabe em protótipos da tendência cientificista moderna hegemônica.

A pluralidade que aqui se faz presente é a da vida cotidiana, que não cabe em único referencial, em uma única teoria, em uma única verdade; nem em uma prática metodológica ou cotidiana. [...] Aceitamos o risco que ela nos traz, de jamais permitir conclusões e fechamentos, de jamais permitir afirmar uma certeza metodológica ou epistemológica, porque acreditamos no plural, no múltiplo, no dinâmico, no permanente móvel e não aprisionável, seja a vida cotidiana de todo praticante, seja na produção acadêmica (FERRAÇO; PEREZ; OLIVEIRA; 2008, p. 16).

Diante disso, pesquisar com é apostar que conceitos e problematizações são possíveis mas, ao mesmo tempo, admitir que não existem verdades únicas ou absolutas e nem as queremos fazerem existir. O cotidiano acontece em meio às situações corriqueiras, ao que está sendo feito, nos entrelaçamentos das redes de relações nos diferentes tempos-espaços vividos. Pesquisar com é a alternativa para superar as tentativas de engessamento das práticas sociais e para admirar a complexidade afeta à cotidianidade.

\section{Por um currículo involutivo}

Nessa perspectiva, vemos serem inventados novos/outros possíveis que fazem da pesquisa uma escrita inquietada: "Essa constitui a dimensão propriamente micropolítica do texto, sua natureza cartográfica" (ROLNIK, 2007, p. 13). As fragmentações, as rupturas e as descontinuidades são deslocamentos intensificadores das produções curriculares e se tornam 
para nós mais uma possibilidade na discussão do caráter unificador do currículo nacional pautado na temporalidade, na estabilidade e na sequencialidade. Quando falamos em um currículo vivo, tecido por sujeitos vivos, fazemos interrupções nas linearidades harmoniosas e admitimos que às redes curriculares cabem as complexificações que lhes são inerentes.

Devido ao poder impositivo do que é construído nas escalas das macropolíticas, apostamos nas lutas minoritárias e micropolíticas de um currículo também entretecido nas multiplicidades dos detalhes cotidianos, imperceptíveis aos olhos de quem arquiteta os grandes projetos educacionais, tão gelados e distantes do que é vivido coletivamente na educação. Dessa maneira, com Deleuze e Guattari (2011), sublinhamos a não-oposição e o não-dualismo entre rizoma e árvore, estriado e liso, menor e maior, prescrito e inventado, nômade e sedentário. Essas composições tecem as redes curriculares e constituem nosso espaço-tempo de pesquisa, até porque,

[...] será que nós não restauramos um simples dualismo opondo os mapas aos decalques, como um bom e um mau lado? Não é próprio do mapa poder ser decalcado? Não é próprio de um rizoma cruzar as raízes, confundir-se às vezes com elas? Um mapa não comporta fenômenos de redundância que já são como que seus próprios decalques? Uma multiplicidade não tem seus estratos onde se enraízam unificações e totalizações, massificações, mecanismos miméticos, tomadas de poder significantes, atribuições subjetivas? (DELEUZE; GUATTARI, 2011, p. 31).

Ousamos assumir as fragmentações como intensidades e, colocando sob suspeita o pseudoequilíbrio proposto pelos currículos vigentes, evidenciamos que as rupturas são linhas de fuga revelativas de que o rizoma-educação não supõe qualquer processo de significação ou de hierarquização. Um rizoma pode ser rompido, quebrado em um lugar qualquer e pode retornar nas suas próprias linhas ou em outras: linhas de segmentaridade e de estratificação, mas, ao mesmo tempo, que aparecem como linhas de fuga e de desterritorialização de cada vida-corpo.

Enquanto docentes produzimos, por muitas vezes, práticas-políticas curriculares que, provocadas pelos planos de uma ciência régia em suas formas e forças rígidas, vão metamorfoseando $e$ atravessando $e$ produzindo afecções na composição-encontro dos corpos. Em tal composição, na efemeridade da vida, são experimentados os diferentes modos de existência, articulados aos processos de subjetivação que imanentemente resistem ao instituído, cartografando, assim, práticas-políticas docentes que compõem em defesa daquilo que acreditamos e sentimos. Afinal, os movimentos (in)voluntários são compostos pelas linhas molares e pelas moleculares, pelos espaços lisos e pelos estriados, pelos territórios/desterritórios/reterritórios, pelas macro-micro políticas, isto é, pelos dispositivos que coexistem num fluxo contínuo de se (re)pensar a docência-nômade.

Movimentos (in)voluntários, que quando experimentados e sentidos, nos localizam no avesso de uma vida que estávamos territorializados a viver, ou seja, um diferente modo de existência. Avesso de uma vida? O que seria o avesso de uma vida? Talvez, linhas de fugas dos modelos que carregamos dos processos formativos pautados na ciência régia, seria um bom argumento para as indagações que nos atravessam. Pois, "[...] há sempre uma corrente a qual as ciências ambulantes ou itinerantes não se deixam interiorizar completamente nas ciências regias reprodutoras" (DELEUZE; GUATTARI, 2012b, p. 43). Acreditamos que práticas-políticas docentes que rompem com o instituído estão sendo produzidas pelas ciências ambulantes ou itinerantes, ao passo que, "[...] nas ciências ambulantes ou nômades, a ciência não está destinada a tomar um poder [...] porque subordinam todas as suas operações às condições sensíveis da intuição e da construção, seguir o fluxo de matéria, traçar e conectar o espaço liso" (Ibidem, p. 41). 
Um emaranhado de tensões, inquietações, contratempos que uma vida-corpo se encarrega de agenciar a existência, em meios aos pontos, fios e interstícios. Enfim, são múltiplos e diferentes currículos que, na sua complexidade, desafiam em seguir os fluxos de uma vida imanente que apostamos e escolhemos a viver. Isto é, trata-se sempre de liberar a vida lá onde ela é prisioneira, ou de tentar fazê-lo num combate incerto (DELEUZE; GUATTARI, 1992).

Pertencentes as múltiplas e diferentes redes de modos de produções curriculares por meio de uma vida-corpo. Pautamos esta escrita-ensaio no pesquisar pelo viés de uma ciência nômade, na tentativa de subverter a ciência régia, esta pautada na educação-pedagogia-escola nos modelos hegemônicos e clássicos de se pensar e fazer educação. Ao contrário, quando entendemos os possíveis e efêmeros movimentos de uma vida-corpo é que pensamos numa concepção de ciêncianômade, tendo como intercessão Deleuze e Guattari (2012b, p. 27), "Bem mais, essa ciência nômade não pára de ser 'barrada', inibida ou proibida pelas exigências e condições da ciência de Estado." Tal pensamento passa a ser uma experiência de resistência ao presente, fundada na vocação política, em meio a um estilo minoritário de viver. E aqui podemos provisoriamente apresentar este pensamento intempestivo como uma experiência do fora, colocando em evidência seus traços nômades, seu caráter revolucionário, para problematizar e visibilizar o conceito que queremos defender, uma vida-corpo em sua efemeridade.

Problematizar currículos que atravessam vidas-corpos nos fluxos dos acontecimentos, dos desejos, das afecções e do caos em sua transitoriedade, provocando alterações das linhas que desejamos cartografar, com uma intensidade de forças nos movimentos de idas e vindas, encontros e desencontros, chegadas e partidas... Uma vida-corpo... Currículo(s)...

Desta maneira, desejamos pensar com as práticas-políticas curriculares que acontecem em escolas públicas na sua complexidade, pois acreditamos que as múltiplas relações em diferentes espaços-tempos são os possíveis para os movimentos da composição de um vidacorpo em um currículo involutivo. Inspirados por tais problematizações é que somos convidados a apreender os movimentos que tensionam os conflitos entre uma vida-corpo-vida provenientes das linhas imanentes aos acontecimentos que bordam com outros fios, sentidos, cores e vidas que incorporam vidas em seus processos de subjetivação de uma vida-corpo.

\section{(Im)possibilidades de concluir}

Os espaços-tempos de ensinar-aprender-ensinar são aqui considerados como interstícios em que as negociações culturais ocorrem. Novas formas de ver as configurações da escola e seus currículos são possíveis aí e o conhecimento invisibilizado pode cortar o conhecimento régio, em movimentos de trocas intensas e de complexas hibridizações que transformam continuamente uma vida-corpo. Diante disso, as rupturas fazem as estruturas vazarem e "Por isso, o mais importante talvez sejam os fenômenos fronteiriços onde a ciência nômade exerce uma pressão sobre a ciência de Estado, e onde, inversamente, a ciência de Estado se apropria e transforma os dados da ciência nômade" (DELEUZE; GUATTARI, 2012b, p. 28).

Como zonas imanentes, as fronteiras são lugares de devir e afirmam a potência da ruptura. Linhas que se quebram e conectam novamente em qualquer ponto, desfazendo a mesmice e fazendo fugir... Docência... Nomadismo... Inquietude... Por isso, as linhas de fuga são tão interessantes: elas desorganizam os modelos estruturais e criam novos espaços-tempos, perfeitamente improgramáveis e inéditos, que se abrem à descoberta de mundos.

São essas fugas criativas e perigosas que potencializam esta pesquisa, que intensificam o sentir, forçando-nos a pensar diferente. Currículo constituído na imanência, na transversalidade, em qualquer lugar, em qualquer tempo, cotidianamente. Aspiramos ver validados os conhecimentos que são tecidos em uma escala menor e que se propagam de forma assustadora, porque eles são 
simplesmente agenciamentos que não fixam lugares e que só podem ser apreciados no minúsculo, nos detalhes. Portanto, propomos a possibilidade de um pensamento da diferença, que permita que as fronteiras sejam esfumaçadas. Assim, por mais que se queira separar, é impossível impedir os acontecimentos cotidianos. Estamos falando de sujeitos orquestrados por um devir-corpo, que pouco se importam com o que os outros pensam deles ou para eles. Composições.

Currículos tecidos por professores em suas mais diversas docências-nômades, que usam o instituído para reinventar novos e outros modos de fazer educação pública, aliando molar e molecular na defesa da sua própria prática-política, que não está escrita ou impressa nos grandes arranjos das políticas curriculares. Um devir-involutivo que nos conduz à percepção de vidascorpos que não podem ser engessadas ou transformadas em números, quantitativos, índices. São invencionices únicas-múltiplas de um conhecedor que resiste e arma sua trincheira para defender seu território, que nem sempre é seu.

Um inegável convite de um mover-se ao contrário, andar na contramão, de ousar considerar uma temporalidade (des)contínua, permitindo-nos, em nosso devir-pesquisador(a), uma verdadeira desterritorialização de conhecimentos, pensamentos, sentidos e pulsações para que possamos, revisitar os nossos vazios que, de certa maneira, habitam algumas tensões, crenças e experiências que coexistem com outros mundos, em nossos corpos e que produzem diferentes cenas. Que corpo é esse? Ou, que corpos são esses? O que podem esses corpos nos currículos cotidianos das escolas? Não temos respostas. Mantemos as perguntas.

\section{Referências}

DELEUZE, Gilles. Lógica do sentido. São Paulo: Perspectiva, 1974.

DELEUZE, Gilles. Espinosa: filosofia prática. São Paulo: Escuta, 2002.

DELEUZE, Gilles. O abecedário de Gilles Deleuze. Entrevista concedida a Claire Parnet. Escrito por Bernardo Rieux. Paris: Éditions Montparnasse, 2005. Disponível em: http://stoa.usp.br/prodsubjeduc/files/262/1015/Abecedario+G.+Deleuze.pdf. Acesso em: 13 fev. 2020.

DELEUZE, Gilles. Diferença e repetição. Rio de Janeiro: Graal, 2006.

DELEUZE, Gilles; GUATARRI, Félix. O que é filosofia? Rio de Janeiro: Editora 34, 1992.

DELEUZE, Gilles; GUATARRI, Félix. Mil platôs, vol. 1. São Paulo: Editora 34, 2011.

DELEUZE, Gilles; GUATARRI. Mil platôs, vol. 4. São Paulo: Editora 34, 2012a.

DELEUZE, Gilles; GUATARRI. Mil platôs, vol. 5. São Paulo: Editora 34, 2012b.

DELEUZE, Gilles; GUATARRI, Félix. Kafka: por uma literatura menor. Belo Horizonte: Autêntica, 2017.

DELEUZE, Gilles; PARNET, Claire. Diálogos. São Paulo: Escuta, 1998.

FERRAÇO, Carlos Eduardo. Eu, caçador de mim. In: GARCIA, Regina Leite (Org.). Método: pesquisa com o cotidiano. Rio de Janeiro: DP\&A, 2003. p. 157-175. 
FERRAÇO, Carlos Eduardo. Currículo, formação continuada de professores e cotidiano escolar: fragmentos de complexidade das redes vividas. In: FERRAÇO, Carlos Eduardo (Org.). Cotidiano escolar, formação de professores (as) e currículo. São Paulo: Cortez, 2005. p. 15-41.

FERRAÇO, Carlos Eduardo. Os sujeitos das escolas e a complexidade de seus fazeressaberes: fragmentos das redes tecidas em pesquisas com o cotidiano. In: GARCIA, Regina Leite; ZACCUR, Edwiges (Org.). Cotidiano e diferentes saberes. Rio de Janeiro: DP et Alli, 2006. p. 151- 179.

FERRAÇO, Carlos Eduardo. Apresentação: currículo e imagem e narrativa e rede e experiência e diferença e/ou sobre conversas, encontros e devires. In: FERRAÇO, Carlos Eduardo (Org.). Currículo e educação básica: por entre redes de conhecimentos, imagens, narrativas, experiências e devires. Rio de Janeiro: Rovelle, 2011. p. 11-16.

FERRAÇO, Carlos Eduardo; PEREZ, Carmem Lúcia Vidal; OLIVEIRA, Inês Barbosa de. Diferentes abordagens, temas e modos de ser da pesquisa nos/dos/com os cotidianos. In: FERRAÇO, C. E.; PEREZ, C. L. V.; OLIVEIRA, I. B. (Org.). Aprendizagens cotidianas com a pesquisa: novas reflexões em pesquisa nos/dos/com os cotidianos das escolas. Petrópolis: DP et Alli, 2008. p. 15-21.

GUATTARI, Félix; ROLNIK, Suely. Micropolítica: cartografias do desejo. 12. ed. 4. reimp. Petrópolis: Vozes, 2017.

ROLNIK, Suely. Cartografia sentimental: transformações contemporâneas do desejo. Porto Alegre: Sulina, 2007. 